\title{
Role of Goblet Cells in Intestinal Barrier and Mucosal Immunity
}

\author{
Songwei Yang' \\ Min $Y u$ iD $^{2}$ \\ 'Key Laboratory for Biorheological \\ Science and Technology of Ministry of \\ Education (Chongqing University), \\ Chongqing University Cancer Hospital, \\ Chongqing, 400030, People's Republic of \\ China; ${ }^{2}$ Department of General Surgery, \\ Xinqiao Hospital, Third Military Medical \\ University, Chongqing, 400037, People's \\ Republic of China
}

\begin{abstract}
Goblet cells and the mucus they secrete serve as an important barrier, preventing pathogens from invading the mucosa to cause intestinal inflammation. The perspective regarding goblet cells and mucus has changed, with current evidence suggesting that they are not passive but play a positive role in maintaining intestinal tract immunity and mucosal homeostasis. Goblet cells could obtain luminal antigens, presenting them to the underlying antigen-presenting cells (APCs) that induces adaptive immune responses. Various immunomodulatory factors can promote the differentiation and maturation of goblet cells, and the secretion of mucin. The abnormal proliferation and differentiation of goblet cells, as well as the deficiency synthesis and secretion of mucins, result in intestinal mucosal barrier dysfunction. This review provides an extensive outline of the signaling pathways that regulate goblet cell proliferation and differentiation and control mucins synthesis and secretion to elucidate how altering these pathways affects goblet functionality. Furthermore, the interaction between mucins and goblet cells in intestinal mucosal immunology is described. Therefore, the contribution of goblet cells and mucus in promoting gut defense and homeostasis is illustrated, while clarifying the regulatory mechanisms involved may allow the development of new therapeutic strategies for intestinal disorders.
\end{abstract}

Keywords: goblet cell, intestinal tract, intestinal barrier, mucosal immunity, cytokine, Mucin2

\section{Introduction}

The intestinal tract is essential in controlling nutrient digestion and absorption while functioning as a barrier to prevent foreign antigens and pathogens from entering the mucosal tissues and maintaining intestinal homeostasis. The intestinal barrier system depends on interactions among several barrier components, including mucus layer, epithelial layer and intercellular tight junctions and the lamina propria underneath. ${ }^{1,2}$ Among these components, the integrity of the mucus barrier formed by goblet cells and their secretions play a vital role in maintaining intestinal homeostasis. Goblet cells secrete mucins, which are high-molecular-weight glycoproteins, denoting the primary structural element of the mucus layer. ${ }^{3,4}$ The mucins are highly hydrophilic and can bind water to form a gel-like structure, preventing direct contact between enterocytes and the intraluminal content, especially pathogenic microorganisms. ${ }^{4}$ The absence of or any defect in the mucus layer allows a large number of bacteria to make contact with the epithelial cells, triggering an excessive immune response in the host, ${ }^{5}$ leading to colitis in mice. ${ }^{6}$ Various intestinal infections resulting from parasites, ${ }^{7,8}$ viruses, ${ }^{9}$ and bacteria ${ }^{10}$ modify the production of mucin and goblet cells, demonstrating the importance of the mucus
Correspondence: Songwei Yang; Min Yu $\mathrm{Tel} / \mathrm{Fax}+8623-653-10296$; $+8623-687-55705$

Email yangsongwei0I@I26.com; yumimianbao@163.com 
layer in separating the luminal contents from the epithelium. However, the critical function of the mucus layer and goblet cells in host defense has not received adequate attention. Recent studies have started to focus on the ability of goblet cells to actively sense and respond to infections while secreting additional products, such as trefoil factor peptides (TFF), mucins, Fc- $\gamma$ binding protein (Fcgbp), and resistin-like molecule $\beta$ (RELM $\beta$ ), which are crucial in promoting intestinal defense. ${ }^{11-13}$ This review summarizes the current advancements regarding the signaling pathways that control goblet cell differentiation while discussing the new functional responsibility of goblet cells in intestinal mucosal immunology.

\section{The Differentiation of Goblet Cells}

The self-renewal of intestinal epithelial cells is maintained by the proliferative activity of adult stem cells located at the base of the intestinal crypts. The progeny of these stem cells proliferates and then differentiates into functional epithelial subtypes that migrate to the villi and eventually into the lumen shed into the gut lumen. ${ }^{14,15}$ The four main types, namely Paneth cells, intestinal epithelial cells, enteroendocrine cells, and goblet cells, are derived from the stem cells in the basement of the crypt. ${ }^{11}$ Enterocytes represent the majority (up to $80 \%$ ) of cells in the intestinal epithelium, they are responsible for ion, water, sugar, peptide and lipid uptake. ${ }^{15}$ The basal part of endocrine cells contains a large number of dense neuroendocrine granules, which contain the secreted peptide hormones, secreted basally in an endocrine or paracrine manner. ${ }^{16}$ The goblet cell contains mucigen granules that are expelled to the surface as intestinal mucus, protecting and lubricating the mucosa. Paneth cells are primarily located in the small intestine, where they secrete a number of mediators of host defense, including lysozyme, tumor necrosis factor, and defensins, that protect against intestinal bacterial pathogens. ${ }^{17}$ Dynamic analysis of the goblet cells in the intestines of mice indicated a migration from the crypt base to the villi tip once after differentiation, where they enter the lumen. ${ }^{18,19}$ The upper crypt cells of the colon show that during differentiation, the goblet cells develop the capacity to generate and store significant quantities of mucus. ${ }^{5}$ These immature goblet cells are located at the base of the crypt in a pyramidal shape. ${ }^{18}$ The goblet cell cannot be distinguished morphologically in Mucin2 (Muc2) deficient mice, despite the continued presence of other goblet cell products, such as $\mathrm{TFF}^{20}$ Maintaining stem cells and the distinction into four main types of intestinal cell lineages involves a variety of complex signaling pathways, such as Wnt/ $\beta$-catenin, Notch, PI3-kinase/Akt, and bone morphogenetic protein (BMP) signaling. ${ }^{21}$ The canonical Wnt pathway is tightly linked with cell proliferation, differentiation and stem cell maintenance. ${ }^{15,22}$ Wnt ligands bind to the Frizzled-LRP5-LRP6 receptor complex, which inhibits continuous destruction of $\beta$-catenin by the cytoplasmic adenomatous polyposis coli (APC) destruction complex in the intestinal epithelium. ${ }^{23}$ The accumulation of $\beta$-catenin leads to its translocation to the nucleus, where it binds $\mathrm{T}$ cell factors (TCFs) and directly regulates gene expression. ${ }^{23}$ Using transgenic mice ectopically expressing Dickkopf1 (Dkk1), a secreted Wnt inhibitor, Pinto et $\mathrm{al}^{24}$ found that epithelial proliferation is highly reduced simultaneously with the loss of crypts. Although enterocyte differentiation appeared unaffected, secretory cell lineages were largely absent. In the presence of WNT, stabilized $\beta$ catenin can bind the Hes1 promoter together with Notch intracellular domain (NICD), resulting in stable Notch activation and promoting the initial absorptive or secretory cell differentiation decision by lateral inhibition. ${ }^{25,26}$ Higher up in the crypt, in the absence of WNT, negative feedback of the Hes1 promoter and absence of nuclear $\beta$ catenin causes oscillatory Notch activation and enables stochastic secondary fate decisions within a lineage (for example goblet versus enteroendocrine cell fate ${ }^{26}$ ). The Notch signaling pathway significantly regulates intestinal enterocyte lineage, activating the hairy and enhancer of split 1 (Hes1) transcription factor, repressing the basic helix-loop-helix (bHLH) transcription factor mouse atonal homolog 1 (Math1), ${ }^{11,27}$ also known as Atonal homologue 1 (Atoh1). The Notch-Hes1 pathway promotes intestinal progenitor cell differentiation toward luminal epithelial cells, restricting the development of secretory cells. Notch signaling pathway activation disrupts the differentiation of secretory cells with the villi coated primarily with absorptive enterocytes associated with Hes1 activation. ${ }^{11,21}$ Math1 facilitates the distinction of intestinal stem cells into the goblet cell lineage and is seemingly essential for differentiating intestinal secretory lineages since studies have shown that Math1-deficient mice failed to generate three gastrointestinal mucosal cell types, namely enteroendocrine, Paneth, and goblet cells. ${ }^{18,28}$ As indicated by previous research, the transcriptional activation of the Jagged1 Notch-ligand, mediated by $\beta$-catenin, leads to Notch being downstream of Wnt in colorectal cancer cells. ${ }^{29,30}$ Furthermore, the terminal differentiation of goblet cells involves the activation of Krüppel-like transcription factor 
4 (Klf4), SAM pointed domain-containing ETS transcription factor (Spdef), and growth factor independence 1 (Gfil). As a downstream target of Math1, Gfil controls intestinal secretory cell subtype allocation and differentiation. ${ }^{31}$ Furthermore, fewer supernumerary enteroendocrine and goblet cells were evident in Gfil knockout mice, while they lacked Paneth cells. Gfil-null crypts containing no Paneth cells and only a few goblet cells display a quantitative reduction in Spdef, which is absent from Atoh1-null crypts lacking intestinal secretory cells, suggesting Spdef functionality downstream of Gfil and Math1 in the goblet cell terminal differentiation pathway $^{32}$ (Figure 1). In the intestine, Klf4 regulates goblet cell terminal differentiation by controlling Muc2 expression, ${ }^{33}$ which can be inhibited by the Notch signaling pathway. ${ }^{34}$ Recent studies indicate that prolyl hydroxylase 3 (PHD3) also controls the generation of intestine goblet cell by bounding the E3 ubiquitin ligase HUWE1 and inhibition of HUWE1-mediated ubiquitination and degradation of ATOH1. ${ }^{35}$

Various additional factors, such as immune cells, diet, and bacteria, also influence goblet cell differentiation. ${ }^{36-38}$ Significantly fewer intestinal goblet cells in germ-free mice only express modest levels of MUC2 while containing an exceedingly thin mucus layer compared with conventionally housed mice. ${ }^{39}$ However, exposing germ-free mice to a conventional environment enhances RELM $\beta$ and MUC2 expression, leading to a substantially thicker mucus layer. ${ }^{40}$ The microbiota, acting via secreted factors related to indole, promote goblet cell differentiation and regulate intestinal homeostasis via the xenobiotic aryl hydrocarbon receptor to increase expression of the cytokine interleukin-
10 (IL-10), reversing an effect of aging in geriatric mice. ${ }^{41}$ Therefore, these results support the vital role of microbial colonization in goblet cell development and maturation.

\section{The Classification and Structure of Mucins}

Mucins consist of large glycoproteins containing tandem repeats with high levels of serine and threonine, with the hydroxyl residues displaying a significant number of O-linked oligosaccharides. ${ }^{4}$ To date, 21 different mucin genes have been detected, designated MUC1 to MUC21 according to the order of their discovery. ${ }^{42}$ Furthermore, based on their structural characteristics and biological functionality, mucins are segregated into two primary groups, namely membrane-associated mucins and secreted mucins. Intestinal membrane-associated mucins are denoted by MUC1, MUC3A/B, MUC4, MUC12, MUC13, MUC15, MUC17, MUC20, and MUC21. Secreted mucins can be divided into gel-forming mucins (MUC2, MUC5AC, MUC5B, MUC6, and MUC19), which are essential during the development of the mucus barrier on mucosal surfaces, and non-gel forming mucins (MUC7, MUC8, and MUC9). ${ }^{42-46}$ Gel-forming mucins play a functional protective, transportation, lubrication, and hydration role in the mucous membranes. ${ }^{47}$ Minimal information is available regarding the functionality of non-gel forming mucins. Membrane mucins provide a safe epithelial cell barrier while playing an important role in signal transduction. ${ }^{43}$ A summary of the mucin classification is listed in Table 1.

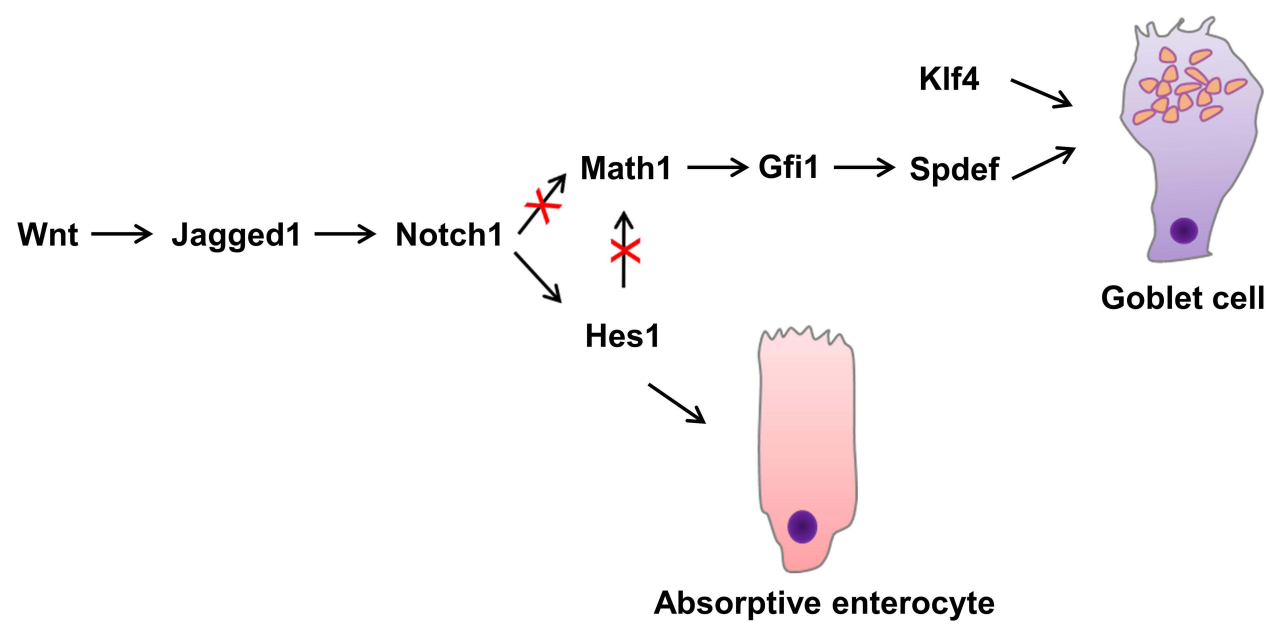

Figure I Role of transcription factors in goblet cell differentiation. 
Table I The Classification of Mucins

\begin{tabular}{|c|c|c|}
\hline \multicolumn{2}{|c|}{ Subfamily } & MUC Gene \\
\hline \multicolumn{2}{|c|}{ Membrane bound } & MUCI, MUC3, MUC4, MUCI0, MUCII, \\
\hline \multirow[t]{2}{*}{ Secreted } & $\begin{array}{l}\text { Gel- } \\
\text { forming }\end{array}$ & MUC2, MUC5AC, MUC5B, MUC6, MUCI9 \\
\hline & $\begin{array}{l}\text { Non Gel- } \\
\text { forming }\end{array}$ & MUC7, MUC8, MUC9 \\
\hline
\end{tabular}

\section{Regulation of Mucin Synthesis}

The endoplasmic reticulum (ER) represents the organelle where mucins are synthesized, and $\mathrm{N}$-linked glycosylation occurs. The assembled mucins are transported to the Golgi complex, where they are O-linked glycosylated to a size of 2.5 million Daltons. ${ }^{48-50}$ They are then packaged as secretory granules, accounting for about $75 \%$ of the cytoplasmic volume. ${ }^{51}$ The granules mature to produce highly concentrated mucins that eventually merge with the plasma membrane and are secreted into the extracellular domain. ${ }^{52}$ The mucin structure changes to form a gelatinous combination with water, covering the surface of the epithelium. ${ }^{49}$ MUC2 denotes the prominent intestinal mucin secreted by healthy mice, the deficiency of which leads to spontaneous inflammation and infection susceptibility. ${ }^{6}$

Recent studies have revealed that epigenetic and transcriptional regulation primarily controls the expression of mucin. ${ }^{43,47,53}$ Signaling pathways control Muc2 transcriptional regulation, activating the transcription factors binding to specific Muc2 promoter sites. Negative or positive Muc2 transcription is reportedly regulated by several biologically active molecules, including growth factors, hormones, microbial products, and cytokines. ${ }^{43}$ Muc2 gene expression regulation is essentially governed by the promoter region. The promoter structures of Muc2 reveal that a typical TATA box exists at the $31 /-25$ bp upstream location of the transcriptional initiation site. ${ }^{54,55}$ The Muc2 gene 5 '-flanking areas display a CACCC box that specifically binds to the specificity protein $1(\mathrm{Sp} 1)$ transcription factor. In addition, transcription factor p53 can activate the transcription of
Muc2 by binding to both the $-1131 /-1100$ and $-676 /$ -650 sites. ${ }^{56}$ Moreover, NF- $\mathrm{KB}$ is also associated with the upregulation of Muc2 transcription, ${ }^{57}$ representing the final effector molecule that regulates Muc2 expression in multiple signaling pathways (Figure 2).

Many other factors impact the expression of Muc2 by directly binding on different sites of the promoter, including short-chain fatty acids (SCFAs) ${ }^{58}$ galectin$3,{ }^{59}$ homeobox domains $(\mathrm{Cdx}),{ }^{60}$ the GATA family, ${ }^{61}$ and HATH1. ${ }^{62}$ SCFAs are metabolites formed by gut microbiota from dietary fiber, including acetate, propionate, and butyrate. ${ }^{63}$ As part of the $\beta$-galactoside-binding gene family, galectin-3 is implicated in tumor progression, cell migration, adhesion, and apoptosis. ${ }^{59,64}$ Both butyrate and galectin-3 stimulate Muc2 expression through the AP-1 transcription factor binding site in the Muc2 promoter. ${ }^{58,65} \mathrm{AP}-1$ is a dimeric protein complex that consists of c-Jun and c-Fos proto-oncogenes, the expression of which can be facilitated by butyrate. ${ }^{58}$ Two Cdx-2 binding sites are present in the Muc2 promoter at $-177 /-171$ and $-191 /-187$, suggesting that Cdx2 is a transcriptional regulator for Muc2 ${ }^{60}$ GATA exists in the Muc2 gene $5^{\prime}$-flanking region and comprises six transcription factors in the highly conserved zinc finger DNA-binding domain, which is responsible for upregulating Muc2 gene expression. ${ }^{61,66}$ HATH1 and MATH1 are bHLH transcription factors essential in regulating the differentiation of goblet cells. ${ }^{18,28}$ HATH1 binding sites are present in the Muc2 promoter sequence, the mutation of which down-regulates the expression of Muc2. ${ }^{62}$

Some bacterial products regulate the production of Muc2 indirectly by activating the NF-kB pathway, including lipopolysaccharides (LPS), Gram-negative bacterial flagellin A, and Gram-positive bacterial lipoteichoic acid (LTA). Muc2 transcription is upregulated by Gramnegative Pseudomonas aeruginosa LPS by activating $\mathrm{NF}-\mathrm{kB}$ via the Ras-mitogen-activated protein kinase (MAPK) pathway in the intestinal epithelial cells. ${ }^{57,67}$ However, flagellin binds to the Asialo-GM1 glycolipid receptor on the surface, releasing ATP and subsequently binding to the cell surface $G$ protein-coupled receptor (GPCR). This increases the intracellular calcium levels,

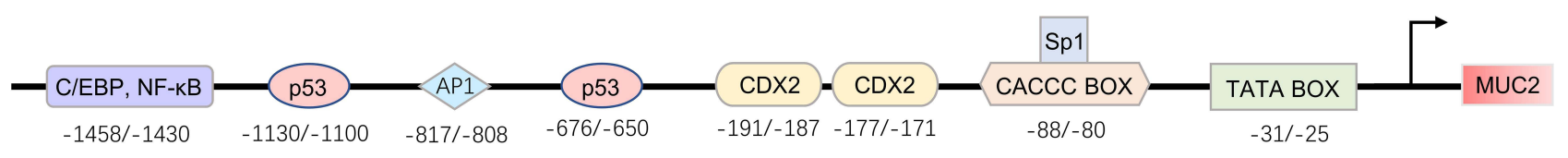

Figure 2 Schematic representation of the promoter regions of MUC2. 
activating NF- $\mathrm{B}$ via the downstream signaling pathways. $^{57}$ Furthermore, LTA binds and activates the platelet-activating factor receptor, a cell surface GPCR, inactivating the epidermal growth factor receptor (EGFR), in turn leading to the activation of the Ras/Raf/ $\mathrm{MEK} / \mathrm{ERK} / \mathrm{pp} 90 \mathrm{rsk} / \mathrm{NF}-\mathrm{kB}$ pathway while upregulating the transcription ${ }^{68}$ of Muc2.

Furthermore, several cytokines and chemokines are involved in mucin synthesis. The Th1 type cytokine, tumor necrosis factor- $\alpha$ (TNF- $\alpha)$, upregulates the transcription of Muc2 via the PI3K/AKT/NF- $\mathrm{BB}$ signaling pathway. Moreover, TNF- $\alpha$ also inhibits the transcription of Muc2 through the JNK pathway, but overall effect of is a net increase in Muc2 transcription, because NF- $\kappa \mathrm{B}$ transcriptional activation of this gene is able to counter-balance the suppressive effects of the JNK pathway. ${ }^{69}$ However, TNF$\alpha$ inhibited Muc2 production when NF- $\kappa \mathrm{B}$ was inactivated, which gives rise to the defective mucosal protection. ${ }^{69}$ Vasoactive intestinal peptide (VIP), a neuropeptide hormone, is responsible for the Muc2 transcription upregulation by activating the CREB/ATF1 transcription factors via the p38 and MAPK pathways. ${ }^{70}$ PGE2 also induced Muc2 transcription by activation of CREB/ATF1. The underlying molecular mechanisms of another Th1 type cytokine, IL$1 \beta$, induces the Muc2 activation of the p38 and ERK pathways, leading to cyclooxygenase 2 expression, an enzyme related to PGE2 synthesis. ${ }^{71}$ Moreover, IL-4 and IL-13 are Th2 cytokines that can upregulate the expression of Muc2 through the MAPK/NF- $\kappa$ B mediated pathway. ${ }^{72}$

Epigenetic regulation includes microRNA silencing, histone modification, and DNA methylation. The methylation of specific $\mathrm{CpG}$ sites in the promoter region and first intron of Muc2 is associated with the repression of MUC2. ${ }^{73}$ Recent studies have revealed that the expression of Muc2 gene is controlled by the methylation of DNA and the modification of histone in the $5^{\prime}$ flanking area of the Muc2 promoter. $^{74}$

\section{Regulation of Mucin Secretion}

After mucin proteins are synthesized in the goblet cells, they are tightly packed into intracytoplasmic granules. They are then transported to the surface of the cell and ultimately secreted into the lumen. Mucin secretion can be divided into two types, namely constitutive and stimulated secretion. In typical physiological conditions, goblet cells are synthesized continuously, secreting mucins to form the hydrated gel coating on the intestinal mucosal luminal surface. This continual secretion of mucin is essential for maintaining the thickness of the mucus gel. It is constantly subjected to various microbial pathogens and stimuli and is often shed due to peristaltic intestinal movements. ${ }^{75}$ The release of mucin is accelerated when goblet cells are subjected to powerful secretagogues and is influenced by many different factors, including neuropeptides, cytokines, and lipids. ${ }^{76}$ Bioactive cytokine binds to specific receptor-affecting secondary messengers and signaling components, such as intracellular diacylglycerol, cAMP, and $\mathrm{Ca} 2+$, activating protein kinase $\mathrm{C}$ to promote the secretion ${ }^{67,77}$ of mucin. The prostaglandin E2 (PGE2) immune modulator binds the EP4 receptor, promoting cAMP-dependent exocytosis in the human colon. ${ }^{78,79}$ Carbachol, a Ca2+-mediated agonist, elevates the cytosol levels of $\mathrm{Ca} 2+$, which stimulates the secretion $^{80}$ of mucin. Phorbol 12-myristate 13-acetate (PMA) significantly promotes the release of mucin via the protein-kinase C-dependent pathway. ${ }^{77}$

Recent research has indicated that the mucus secretion of goblet cells is modulated by several cellular processes, including the assembly and activation of inflammasomes, the generation of reactive oxygen species (ROS), ${ }^{4,5,81}$ autophagy, and endocytosis. Previous research has revealed the inhibition of clathrin-mediated endocytosis, as well as defects in autophagy-related proteins, including Atg5, Atg14, and FIP200, resulting in the aggregation of goblet cell mucin granules. ${ }^{4,81}$ Mucin accumulation is not associated with mucin expression, suggesting that this effect might be caused by mucin secretion deficiency.

Recent studies have shown that the secretion of goblet cells relies on autophagy proteins. ${ }^{81}$ The MUC2 granule aggregation in the goblet cells is determined via a targeted villin-driven deficiency of the Atg5 autophagy protein in the intestines of mice. This process is mediated by ROS derived from NADPH oxidases.

The NLR protein, NLRP6, is associated with inflammasome signaling and is essential for maintaining intestinal homeostasis. $^{82,83}$ In NLRP6 knock out mice, goblet cells were less efficient at secreting mucin and had poorer development of the inner mucus layer. ${ }^{83}$ No reduction was evident in the specific protein transcription of goblet cells in NLRP6deficient mice, suggesting that the lack of mucus generation could not be attributed to a decline in transcript production. Conversely, the accumulation of intracellular mucin particles in the distal colon of mice deficient in NLRP6 increased, but these particles failed to merge with the apical surfaces of the goblet cells. NLRP6 deficiency resulted in defective goblet autophagy, reducing mucin secretion into the intestinal lumen. 
Recent reports indicated that some goblet cells localized at the colonic crypt entrance underwent nonspecific endocytosis, known as sentinel goblet cells (senGC). Toll-like receptors (TLR)-ligands, LPS, and P3CSK4 were endocytosed by senGC, triggering TLR-MyD88 signaling and inducing downstream ROS synthesis, causing NLRP6 inflammasomemediated caspase 1 and 11 activation. Furthermore, this led to the $\mathrm{Ca} 2+$-dependent exocytosis of MUC2 and intercellular signaling connections, prompting the secretion of MUC2 by the adjacent responsive GCs. The inhibition of endocytosis or NADPH/Dual oxidase ROS synthesis restricted TLR-ligandinduced Muc2 secretion ${ }^{12,84}$ (Figure 3).

\section{The Interaction Between Goblet Cells and Immune Cells}

Although the main functions of intestinal goblet cells have traditionally been believed to include producing and secreting mucus, recent studies have shown that this is not the case. The intestinal lamina propria (LP) has a large population of dendritic cells, such as CD103- CX3CR1+ antigen-presenting cells (APCs) with macrophage qualities and $\mathrm{CD} 103+$ CX3CR1- APCs with dendritic cell characteristics. ${ }^{85-87}$ In CD103+ APCs, retinaldehyde dehydrogenase (ALDH1) expression is essential for producing all-trans retinoic acid (ATRA), which plays various roles in the mucosal immune response to lumen antigens, such as promoting IgA responses, imprinting lymphocytes with gut homing, and prompting regulatory T cell formation. ${ }^{86,88,89}$ The CD103- CX3CR1+ APCs are crucial for the formation of Th17 T cells, colitis, and the production of TNF- $\alpha .{ }^{90}$ Research has revealed that intestinal epithelial cells can also obtain luminal antigens, presenting them to the dendritic $\mathrm{CD}_{103}{ }^{+}$cells underlying the LP in a way that induced adaptive immune responses, known as goblet-cell-associated antigen passages (GAP cells ${ }^{86,91}$ ).

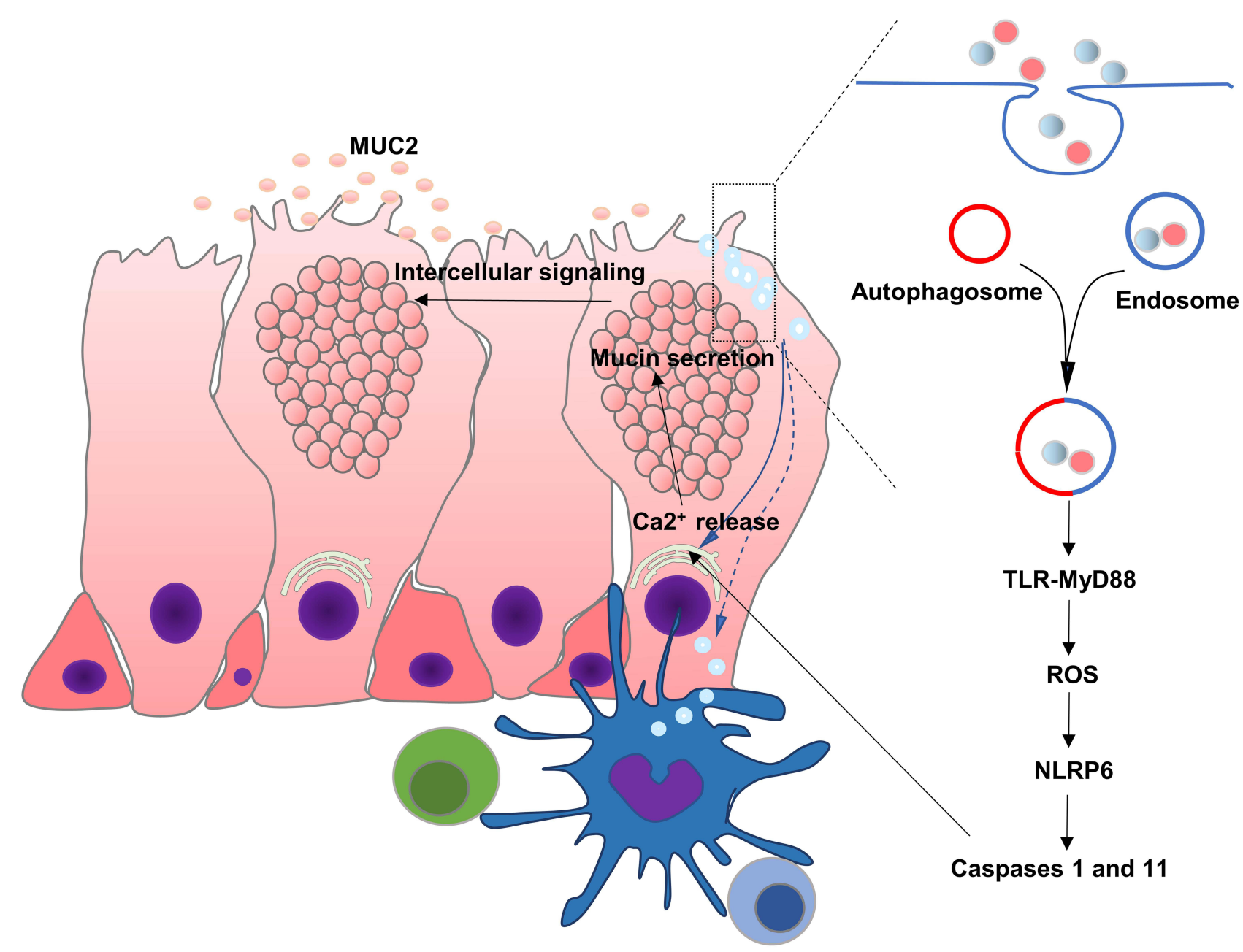

Figure 3 Regulatory mechanism of mucus secretion in goblet cell and interaction with immune cells. Soluble antigens in the lumen of the intestine such as LPS and P3CSK4 are endocytosed by senGC, triggering TLR-MyD88 signaling, ROS synthesis and NLRP6 inflammasome, causing Ca2+-dependent secretion of MUC2. Goblet cells can also deliver luminal antigens to APCs, initiating adaptive responses. 
When acetylcholine (ACh) acts on muscarinic acetylcholine receptor $4(\mathrm{mAChR} 4)$ on the goblet cells, GAPs are formed. ${ }^{92}$ The formation of GAPs occurs in a steady state in the small intestine, but is inhibited by Myd88 dependent microbial sensing in the colon. According to Knoop KA, GAP cells could occur in the colon following treatment with antibiotics, that they were repressed by TLR ligands in a goblet cell intrinsic Myd88-dependent manner. The EGFR and MAPK are activated by Myd88, inhibiting the formation of colon GAPs. Therefore, both $\mathrm{CD}_{103}{ }^{-}$and $\mathrm{CD}_{103}{ }^{+}$dendritic cells, as well as subsequent mucosal inflammation, are activated ${ }^{92}$ (Figure 3).

Goblet cell products and luminal antigens are transferred during the interaction with APCs, imprinting them with mucosal properties. ${ }^{86}$ The primary goblet cell product, MUC2, has been shown to imprint anti-inflammatory gene markers required for oral tolerance on APCs. ${ }^{93}$ Interfering with the APC and epithelial cell interaction reduces the transfer of goblet cell products to APCs, reducing the induction of mucosal reactions. ${ }^{94}$ RELM- $\beta$ is another product secreted by goblet cells, acting as a chemoattractant recruit CD4 T cells to the colon LP when infected with $C$. rodentium ${ }^{95} \mathrm{CD} 4+\mathrm{T}$ cell recruitment to the infected colons of RELM- $\beta$ knockout mice was restricted, reducing IL-22 production, a pluripotent cytokine directly responsible for enhancing the proliferation of epithelial cells. Goblet cells also regulate the immune response by secreting various cytokines, such as IL25, IL18, IL17, IL15, IL13, IL7, and IL6, and chemokine exotoxin, CCL6, CCL9, and CCL20. The latter attract APCs to the epithelium. ${ }^{91,94}$ Therefore, goblet cells establish intimate interactions with immune cells, playing a unique and integral role in maintaining gut immune homeostasis. ${ }^{96}$

\section{Immune Regulation of Goblet Cell Function}

Although goblet cells control the LP via a specific mechanism, the immune system is also essential in regulating goblet cell functionality (Figure 4). Type 3 Innate Lymphoid Cells (ILC3s) promotes goblet cell differentiation and the expression of MUC2 through the lymphotoxin (LT)-LT $\beta$ R pathway during intestinal listeria infection. ${ }^{10,97}$ DCs such as macrophages and dendritic cells provide processed, phagocytosed antigens for activating and instructing naïve CD4+ T cells to convert to type 2 helper (Th2) cells. ${ }^{98,99}$ These cells are essential for the immune response against extracellular parasites and intracellular pathogens, resulting in the increased secretion of cytokines like IL-13, IL-9, IL-5, and IL-4. ${ }^{100-102}$ Of these, IL-4 and
IL-13 are considered the major effector cytokines that signal through the IL-4R $\alpha$ and IL13R $\alpha 1$ subunits on the intestinal epithelial cells to induce goblet cell hyperplasia via the downstream signal transducer and activator of transcription factor 6 (STAT6) signaling. ${ }^{103,104}$ STAT6 is critical for goblet cell hyperplasia development during infection with T. spiralis. ${ }^{18,105}$ STAT6 deficient mice infected with T. spiralis failed to generate infection-induced goblet cell hyperplasia. Further studies have shown that IL-13 is crucial in regulating goblet cell hyperplasia in Gymnophalloides seoi infection. The overexpression of IL-13 in mice causes the development of goblet cell hyperplasia in their intestines. Furthermore, the overexpression of exogenous IL-9 and IL25 promotes goblet cell proliferation and mucin expression via an IL-13-reliant pathway. ${ }^{106}$ The administration of IL-4 enhances the thickness and quality of the mucus while decreasing pathogenic contact with the epithelium in $C$. rodentium and colitis in infected mice. ${ }^{107}$ IL-13 and IL-4 upregulate the expression of specific goblet cell products, TFF3 and MUC2, via STAT6 signaling. ${ }^{108}$ In addition, IL-13 and IL-4 increase the transcription of MUC2 through the MAPK pathway ${ }^{72}$ (Figure 4).

Like Th2 cytokines, some Th1 cytokines regulate mucin biosynthesis, while TNF- $\alpha$ upregulates MUC2 in human intestinal epithelial cells via the NIK and PI3K/Akt signaling pathways converging at the common NF- $\mathrm{KB}$ pathway. ${ }^{69}$ MUC2 was increased in the 3D co-culture model of Caco-2 and HT29-MTX cells when treated with IL-1 $\beta$, while MUC5AC remained unchanged. ${ }^{109}$ By activating PI3K and PKC-MEK/ERK, IL-1 $\beta$ also stimulates the secretion of mucin and the expression of MUC2 genes in the epithelial cells of the human airway. ${ }^{110}$ In contrast, the Th1 cytokines, TNF- $\alpha$ and IFN- $\gamma$, decrease the production of intestinal mucin, as well as the mucin transportation rate from the Golgi to secretory vesicles in the $C$. rodentium infection mode, ${ }^{107}$ implying that the Thl cytokine impact on goblet cells is not only related to the type of cytokines but also pathological conditions.

Studies have shown that the Th17-associated cytokine, IL-22, is essential in regulating the expression of mucin and the differentiation of GC. IL-22 knockout mice fail to increase the expression of MUC2 and reduced goblet cell hyperplasia in N.brasiliensis and T. muris infection. ${ }^{111}$ This is correlated with the reduced induction of TH2 immunity as IL-4, IL-5, and IL-13 declined. ${ }^{112}$ In a mouse colitis model, IL-22 was directly responsible for mucin gene expression in the mucosal epithelial cells via goblet cell restitution and STAT3-reliant signaling, alleviating local intestinal inflammation. ${ }^{13,114}$ 


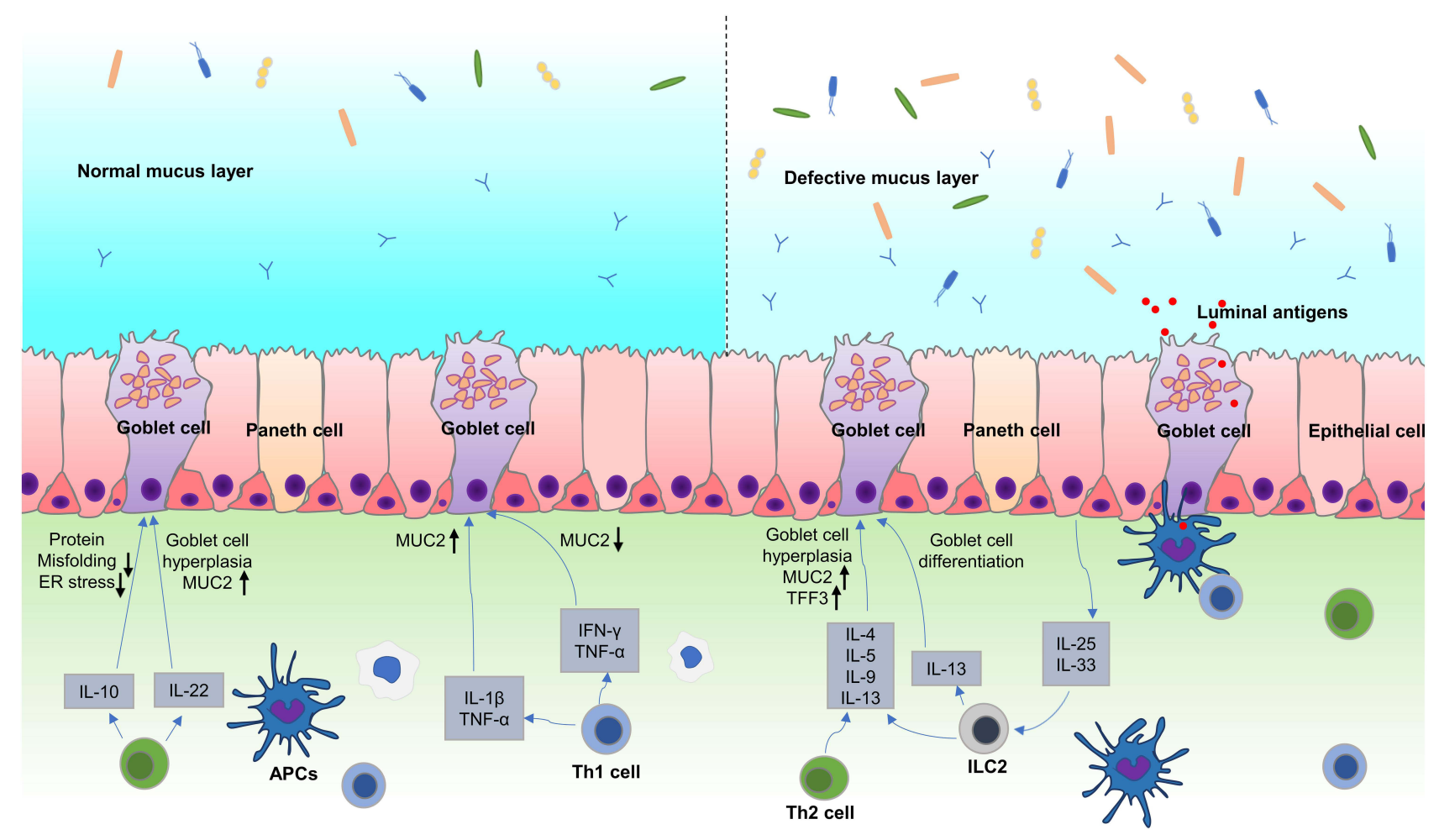

Figure 4 Immune regulation of goblet cell function and mucin production. (I) IL-33 and IL-25 activate ILC2 and Th2 cells during parasite infections, which release Th2 cytokines such as IL-4, IL-5, IL-9, and IL-I3. IL-4 and IL-I3 can promote goblet cell proliferation through STAT6 signaling. IL-4 and IL-I 3 also upregulate the expression of TFF3 and MUC2 via STAT6 or MAPK signaling. IL-25 and IL-9 also promoted goblet cell proliferation and mucin expression through IL-13 dependent pathway. IL-33 induces goblet cell differentiation by stimulating ILCs to produce IL-13. (2) ThI cytokines such as TNF- $\alpha$, IL-I $\beta$ and IFN- $\gamma$ play complex way in regulating mucin biosynthesis, which not only induce, but also inhibit MUC2 expression in different pathophysiological conditions. (3) IL-22 can regulate goblet cell differentiation and induces mucin expression in STAT3 signaling. IL-10 promotes mucin expression by inhibiting protein misfolding and ER stress in goblet cells.

As an anti-inflammatory cytokine, IL-10 inhibits macrophage activation and inflammatory response. ${ }^{115,116}$ The expression of IL-10 in normal subjects was higher than in inflammatory bowel disease (IBD) patients. ${ }^{117} \mathrm{IL}-$ 10 knockout mice were used for the animal inflammation model. ${ }^{118}$ The goblet cell count decreased in IL-10 deficient mice compared with wild-type mice. ${ }^{119}$ Recent studies have also shown that IL-10 has a direct impact on goblet cell mucus production and mucosal characteristics. ${ }^{120}$ Moreover, previous studies suggest that IL-10 restricts ER stress and protein misfolding in goblet cells, enhancing intestinal mucus production. ${ }^{121}$

The IL-1 cytokine, IL-33, increases in response to infection and colitis ${ }^{122}$ while prompting the production of the IL-4, IL-5, and IL-13 Th2 cytokines from innate lymphoid cells (ILCs) and T cells. ${ }^{123}$ IL-33 prevented goblet cell depletion by inhibiting Notch1 signaling in a dextran sulfate sodium (DSS)induced mouse colitis model. ${ }^{124}$ Research has shown that IL33 prompts the production of IL-13 by stimulating ILCs, indirectly inducing epithelial goblet cell differentiation. ${ }^{37}$

\section{Conclusions}

Mucin is the primary secretory product of goblet cells and is responsible for generating mucus layers, protecting against pathogen invasion in the intestinal mucosa. These mucus layers are essential in preventing pathogenic microbial invasion and colonization while establishing commensal intestinal microbiota. In recent years, several studies have examined the molecular mechanisms of mucin biology and the regulatory pathways responsible for the secretion and biosynthesis of mucin. This data can help develop new strategies to treat the abnormal mucin expression that is often present in inflammatory and malignant diseases. Furthermore, while the primary function of goblet cells is to maintain the integrity of the intestinal barrier, the complicated contribution of these cells to mucosal immunity far exceeds the mere secretion of mucus. Notably, goblet cells are now considered active participants in defending the host, reacting to their luminal environment in conjunction with the immune response. This review summarizes the crucial nature of the immune system in regulating the biological 
functions of goblet cells. In conclusion, further research is necessary on how goblet cells control the extracellular environment, interact with the microbiome and its products, and communicate with underlying immunity to clarify the specific mechanisms involved and develop novel therapeutic approaches for intestinal disorders.

\section{Abbreviations}

APCs, antigen-presenting cells; TFF, trefoil factor peptides; Fcgbp, Fc- $\gamma$ binding protein; RELM $\beta$, resistin-like molecule $\beta$; BMP, bone morphogenetic protein; Hes1, hairy and enhancer of split 1; Muc2, Mucin2; Math1, mouse atonal homolog 1; Gfi1, growth factor independence 1; PHD3, prolyl hydroxylase 3; ER, endoplasmic reticulum; SCFAs, short-chain fatty acids; LPS, lipopolysaccharides; LTA, lipoteichoic acids; MAPK, Ras-mitogen-activated protein kinase; GPCR, G protein-coupled receptor; EGFR, epidermal growth factor receptor; TNF- $\alpha$, tumor necrosis factor- $\alpha$; PGE2, prostaglandin E2; ROS, reactive oxygen species; TLR, Toll-like receptors; ACh, acetylcholine; STAT6, signal transducer and activator of transcription factor 6; IBD, inflammatory bowel disease; ILCs, innate lymphoid cells.

\section{Acknowledgments}

This work was supported by the Basic Science and Frontier Technology Project of Chongqing (cstc2018jcyjAX0777 to S.Y.), and the National Natural Science Foundation of China (NSFC 81970468 to M.Y.).

\section{Disclosure}

The authors report no conflicts of interest in this work.

\section{References}

1. Cardoso-Silva D, Delbue D, Itzlinger A, et al. Intestinal barrier function in gluten-related disorders. Nutrients. 2019;11(10):2325. doi:10.3390/nu11102325

2. Suzuki T. Regulation of the intestinal barrier by nutrients: the role of tight junctions. Anim Sci J. 2020;91(1):e13357. doi:10.1111/asj.13357

3. Nowarski R, Jackson R, Gagliani N, et al. Epithelial IL-18 equilibrium controls barrier function in colitis. Cell. 2015;163(6):1444-1456. doi:10.1016/j.cell.2015.10.072

4. Birchenough GM, Johansson ME, Gustafsson JK, Bergstrom JH, Hansson GC. New developments in goblet cell mucus secretion and function. Mucosal Immunol. 2015;8(4):712-719. doi:10.1038/ mi.2015.32

5. Johansson ME, Hansson GC. Is the intestinal goblet cell a major immune cell? Cell Host Microbe. 2014;15(3):251-252. doi:10.1016/j. chom.2014.02.014

6. Van der Sluis M, De Koning BA, De Bruijn AC, et al. Muc2-deficient mice spontaneously develop colitis, indicating that MUC2 is critical for colonic protection. Gastroenterology. 2006;131(1):117-129. doi:10.1053/j.gastro.2006.04.020
7. Khan WI. Physiological changes in the gastrointestinal tract and host protective immunity: learning from the mouse-Trichinella spiralis model. Parasitology. 2008;135(6):671-682. doi:10.1017/ S0031182008004381

8. Hansson GC. Role of mucus layers in gut infection and inflammation. Curr Opin Microbiol. 2012;15(1):57-62. doi:10.1016/j.mib.2011.11.002

9. Cortez V, Boyd DF, Crawford JC, et al. Astrovirus infects actively secreting goblet cells and alters the gut mucus barrier. Nat Commun. 2020;11(1):2097. doi:10.1038/s41467-020-15999-y

10. Pian Y, Chai Q, Ren B, et al. Type 3 innate lymphoid cells direct goblet cell differentiation via the LT-LTbetaR pathway during listeria infection. J Immunol. 2020;205(3):853-863. doi:10.4049/ jimmunol.2000197

11. Kim YS, Ho SB. Intestinal goblet cells and mucins in health and disease: recent insights and progress. Curr Gastroenterol Rep. 2010;12(5):319-330. doi:10.1007/s11894-010-0131-2

12. Birchenough GM, Nystrom EE, Johansson ME, Hansson GC. A sentinel goblet cell guards the colonic crypt by triggering Nlrp6-dependent Muc2 secretion. Science. 2016;352 (6293):1535-1542. doi:10.1126/science.aaf7419

13. Morampudi V, Dalwadi U, Bhinder G, et al. The goblet cell-derived mediator RELM-beta drives spontaneous colitis in Muc2-deficient mice by promoting commensal microbial dysbiosis. Mucosal Immunol. 2016;9(5):1218-1233. doi:10.1038/mi.2015.140

14. Watson AJ, Hughes KR. TNF-alpha-induced intestinal epithelial cell shedding: implications for intestinal barrier function. Ann $N \quad Y \quad$ Acad Sci. 2012;1258(1):1-8. doi:10.1111/j.17496632.2012.06523.x

15. Gehart H, Clevers H. Tales from the crypt: new insights into intestinal stem cells. Nat Rev Gastroenterol Hepatol. 2019;16 (1):19-34. doi:10.1038/s41575-018-0081-y

16. Yen TH, Wright NA. The gastrointestinal tract stem cell niche. Stem Cell Rev. 2006;2(3):203-212. doi:10.1007/s12015-0060048-1

17. Bevins CL, Salzman NH. Paneth cells, antimicrobial peptides and maintenance of intestinal homeostasis. Nat Rev Microbiol. 2011;9 (5):356-368. doi:10.1038/nrmicro2546

18. Kim JJ, Khan WI. Goblet cells and mucins: role in innate defense in enteric infections. Pathogens. 2013;2(1):55-70. doi:10.3390/ pathogens 2010055

19. Merzel J, Leblond CP. Origin and renewal of goblet cells in the epithelium of the mouse small intestine. Am J Anat. 1969;124 (3):281-305. doi:10.1002/aja.1001240303

20. Velcich A, Yang W, Heyer J, et al. Colorectal cancer in mice genetically deficient in the mucin Muc2. Science. 2002;295 (5560):1726-1729. doi:10.1126/science.1069094

21. van der Flier LG, Clevers H. Stem cells, self-renewal, and differentiation in the intestinal epithelium. Annu Rev Physiol. 2009;71 (1):241-260. doi:10.1146/annurev.physiol.010908.163145

22. Gajos-Michniewicz A, Czyz M. WNT signaling in melanoma. Int J Mol Sci. 2020;21(14):4852. doi:10.3390/ijms21144852

23. Nusse R, Clevers H. Wnt/beta-catenin signaling, disease, and emerging therapeutic modalities. Cell. 2017;169(6):985-999. doi:10.1016/j.cell.2017.05.016

24. Pinto D, Gregorieff A, Begthel H, Clevers H. Canonical Wnt signals are essential for homeostasis of the intestinal epithelium. Genes Dev. 2003;17(14):1709-1713. doi:10.1101/gad.267103

25. Yamamizu K, Matsunaga T, Uosaki H, et al. Convergence of Notch and beta-catenin signaling induces arterial fate in vascular progenitors. J Cell Biol. 2010;189(2):325-338. doi:10.1083/ jcb.200904114

26. Kay SK, Harrington HA, Shepherd S, et al. The role of the Hes1 crosstalk hub in Notch-Wnt interactions of the intestinal crypt. PLoS Comput Biol. 2017;13(2):e1005400. doi:10.1371/journal. pcbi. 1005400 
27. Shinoda M, Shin-Ya M, Naito Y, et al. Early-stage blocking of Notch signaling inhibits the depletion of goblet cells in dextran sodium sulfate-induced colitis in mice. $J$ Gastroenterol. 2010;45 (6):608-617. doi:10.1007/s00535-010-0210-z

28. Yang Q, Bermingham NA, Finegold MJ, Zoghbi HY. Requirement of Math1 for secretory cell lineage commitment in the mouse intestine. Science. 2001;294(5549):2155-2158. doi:10.1126/science. 1065718

29. Rodilla V, Villanueva A, Obrador-Hevia A, et al. Jagged1 is the pathological link between Wnt and Notch pathways in colorectal cancer. Proc Natl Acad Sci U S A. 2009;106(15):6315-6320. doi:10.1073/pnas.0813221106

30. Pannequin J, Bonnans C, Delaunay N, et al. The wnt target jagged-1 mediates the activation of notch signaling by progastrin in human colorectal cancer cells. Cancer Res. 2009;69 (15):6065-6073. doi:10.1158/0008-5472.CAN-08-2409

31. Shroyer NF, Wallis D, Venken KJ, Bellen HJ, Zoghbi HY. Gfi1 functions downstream of Math1 to control intestinal secretory cell subtype allocation and differentiation. Genes Dev. 2005;19 (20):2412-2417. doi:10.1101/gad.1353905

32. Noah TK, Kazanjian A, Whitsett J, Shroyer NF. SAM pointed domain ETS factor (SPDEF) regulates terminal differentiation and maturation of intestinal goblet cells. Exp Cell Res. 2010;316 (3):452-465. doi:10.1016/j.yexcr.2009.09.020

33. Katz JP, Perreault N, Goldstein BG, et al. The zinc-finger transcription factor Klf4 is required for terminal differentiation of goblet cells in the colon. Development. 2002;129(11):2619-2628. doi:10.1242/dev.129.11.2619

34. Zheng H, Pritchard DM, Yang X, et al. KLF4 gene expression is inhibited by the notch signaling pathway that controls goblet cell differentiation in mouse gastrointestinal tract. Am J Physiol Gastrointest Liver Physiol. 2009;296(3):G490-498. doi:10.1152/ ajpgi.90393.2008

35. Xu YM, Gao Q, Zhang JZ, et al. Prolyl hydroxylase 3 controls the intestine goblet cell generation through stabilizing ATOH1. Cell Death Differ. 2020;27(7):2131-2142. doi:10.1038/s41418-020-0490-7

36. Becker S, Oelschlaeger TA, Wullaert A, et al. Bacteria regulate intestinal epithelial cell differentiation factors both in vitro and in vivo. $P L O S$ One. 2013;8(2):e55620. doi:10.1371/journal.pone.0055620

37. Waddell A, Vallance JE, Hummel A, Alenghat T, Rosen MJ. IL33 induces murine intestinal goblet cell differentiation indirectly via innate lymphoid cell IL-13 secretion. J Immunol. 2019;202 (2):598-607. doi:10.4049/jimmunol.1800292

38. Wang Q, Zhou Y, Rychahou P, et al. Ketogenesis contributes to intestinal cell differentiation. Cell Death Differ. 2017;24 (3):458-468. doi:10.1038/cdd.2016.142

39. Bergstrom A, Kristensen MB, Bahl MI, et al. Nature of bacterial colonization influences transcription of mucin genes in mice during the first week of life. BMC Res Notes. 2012;5(1):402. doi:10.1186/1756-0500-5-402

40. He W, Wang ML, Jiang HQ, et al. Bacterial colonization leads to the colonic secretion of RELMbeta/FIZZ2, a novel goblet cell-specific protein. Gastroenterology. 2003;125(5):1388-1397. doi:10.1016/j.gastro.2003.07.009

41. Powell DN, Swimm A, Sonowal R, et al. Indoles from the commensal microbiota act via the AHR and IL-10 to tune the cellular composition of the colonic epithelium during aging. Proc Natl Acad Sci U S A. 2020;117(35):21519-21526. doi:10.1073/ pnas. 2003004117

42. Corfield AP. The interaction of the gut microbiota with the mucus barrier in health and disease in human. Microorganisms. 2018;6 (3):78. doi:10.3390/microorganisms6030078

43. Andrianifahanana M, Moniaux N, Batra SK. Regulation of mucin expression: mechanistic aspects and implications for cancer and inflammatory diseases. Biochim Biophys Acta. 2006;1765 (2):189-222. doi:10.1016/j.bbcan.2006.01.002
44. Bobek LA, Tsai H, Biesbrock AR, Levine MJ. Molecular cloning, sequence, and specificity of expression of the gene encoding the low molecular weight human salivary mucin (MUC7). $J$ Biol Chem. 1993;268(27):20563-20569. doi:10.1016/S0021-9258(20) 80762-5

45. Shankar V, Pichan P, Eddy RL Jr., et al. Chromosomal localization of a human mucin gene (MUC8) and cloning of the cDNA corresponding to the carboxy terminus. Am J Respir Cell Mol Biol. 1997;16(3):232-241. doi:10.1165/ajrcmb.16.3.9070607

46. Lapensee L, Paquette Y, Bleau G. Allelic polymorphism and chromosomal localization of the human oviductin gene (MUC9). Fertil Steril. 1997;68(4):702-708. doi:10.1016/S00150282(97)00317-8

47. Theodoropoulos G, Carraway KL. Molecular signaling in the regulation of mucins. J Cell Biochem. 2007;102(5):1103-1116. doi: $10.1002 /$ jcb. 21539

48. Sheehan JK, Kirkham S, Howard M, et al. Identification of molecular intermediates in the assembly pathway of the MUC5AC mucin. J Biol Chem. 2004;279(15):15698-15705. doi:10.1074/jbc.M313241200

49. Thornton DJ, Rousseau K, McGuckin MA. Structure and function of the polymeric mucins in airways mucus. Annu Rev Physiol. 2008;70(1):459-486. doi:10.1146/annurev.physiol.70.113006. 100702

50. Sharpe C, Thornton DJ, Grencis RK. A sticky end for gastrointestinal helminths; the role of the mucus barrier. Parasite Immunol. 2018;40(4):e12517. doi:10.1111/pim.12517

51. Cantero-Recasens G, Butnaru CM, Valverde MA, Naranjo JR, Brouwers N, Malhotra V. KChIP3 coupled to $\mathrm{Ca}(2+)$ oscillations exerts a tonic brake on baseline mucin release in the colon. Elife. 2018;7:7. doi:10.7554/eLife.39729

52. Adler KB, Tuvim MJ, Dickey BF. Regulated mucin secretion from airway epithelial cells. Front Endocrinol (Lausanne). 2013;4:129. doi:10.3389/fendo.2013.00129

53. Mo JS, Alam KJ, Kim HS, Lee YM, Yun KJ, Chae SC. MicroRNA 429 regulates mucin gene expression and secretion in murine model of colitis. J Crohns Colitis. 2016;10(7):837-849. doi:10.1093/ecco-jcc/jjw033

54. Yamashita MSA, Melo EO. Mucin 2 (MUC2) promoter characterization: an overview. Cell Tissue Res. 2018;374(3):455-463. doi:10.1007/s00441-018-2916-9

55. Gum JR, Hicks JW, Kim YS. Identification and characterization of the MUC2 (human intestinal mucin) gene 5 '-flanking region: promoter activity in cultured cells. Biochem J. 1997;325(Pt 1):259-267. doi:10.1042/bj3250259

56. Ookawa K, Kudo T, Aizawa S, Saito H, Tsuchida S. Transcriptional activation of the MUC2 gene by p53. J Biol Chem. 2002;277(50):48270-48275. doi:10.1074/jbc.M207986200

57. Li JD, Feng W, Gallup M, et al. Activation of NF-kappaB via a Src-dependent Ras-MAPK-pp90rsk pathway is required for Pseudomonas aeruginosa-induced mucin overproduction in epithelial cells. Proc Natl Acad Sci U S A. 1998;95 (10):5718-5723. doi:10.1073/pnas.95.10.5718

58. Burger-van Paassen N, Vincent A, Puiman PJ, et al. The regulation of intestinal mucin MUC2 expression by short-chain fatty acids: implications for epithelial protection. Biochem J. 2009;420 (2):211-219. doi:10.1042/BJ20082222

59. Song S, Byrd JC, Mazurek N, Liu K, Koo JS, Bresalier RS. Galectin-3 modulates MUC2 mucin expression in human colon cancer cells at the level of transcription via AP-1 activation. Gastroenterology. 2005;129(5):1581-1591. doi:10.1053/j. gastro.2005.09.002

60. Mesquita P, Jonckheere N, Almeida R, et al. Human MUC2 mucin gene is transcriptionally regulated by $\mathrm{Cdx}$ homeodomain proteins in gastrointestinal carcinoma cell lines. $J$ Biol Chem. 2003;278(51):51549-51556. doi:10.1074/jbc.M309019200 
61. Ren CY, Akiyama Y, Miyake S, Yuasa Y. Transcription factor GATA-5 selectively up-regulates mucin gene expression. $J$ Cancer Res Clin Oncol. 2004;130(5):245-252. doi:10.1007/ s00432-003-0537-4

62. Park ET, Oh HK, Gum JR Jr., et al. HATH1 expression in mucinous cancers of the colorectum and related lesions. Clin Cancer Res. 2006;12(18):5403-5410. doi:10.1158/1078-0432. CCR-06-0573

63. Filippone A, Lanza M, Campolo M, et al. The anti-inflammatory and antioxidant effects of sodium propionate. Int $\mathrm{J} \mathrm{Mol} \mathrm{Sci}$. 2020;21(8). doi:10.3390/ijms21083026

64. Yoshii T, Fukumori T, Honjo Y, Inohara H, Kim HR, Raz A. Galectin-3 phosphorylation is required for its anti-apoptotic function and cell cycle arrest. J Biol Chem. 2002;277(9):6852-6857. doi:10.1074/jbc.M107668200

65. Hatayama H, Iwashita J, Kuwajima A, Abe T. The short chain fatty acid, butyrate, stimulates MUC2 mucin production in the human colon cancer cell line, LS174T. Biochem Biophys Res Commun. 2007;356(3):599-603. doi:10.1016/j.bbrc.2007.03.025

66. van der Sluis M, Melis MH, Jonckheere N, et al. The murine Muc2 mucin gene is transcriptionally regulated by the zinc-finger GATA-4 transcription factor in intestinal cells. Biochem Biophys Res Commun. 2004;325(3):952-960. doi:10.1016/j.bbrc.2004.10.108

67. Dharmani P, Srivastava V, Kissoon-Singh V, Chadee K. Role of intestinal mucins in innate host defense mechanisms against pathogens. J Innate Immun. 2009;1(2):123-135. doi:10.1159/ 000163037

68. Lemjabbar H, Basbaum C. Platelet-activating factor receptor and ADAM10 mediate responses to Staphylococcus aureus in epithelial cells. Nat Med. 2002;8(1):41-46. doi:10.1038/nm0102-41

69. Ahn DH, Crawley SC, Hokari R, et al. TNF-alpha activates MUC2 transcription via NF-kappaB but inhibits via JNK activation. Cell Physiol Biochem. 2005;15(1-4):29-40. doi:10.1159/000083636

70. Hokari R, Lee H, Crawley SC, et al. Vasoactive intestinal peptide upregulates MUC2 intestinal mucin via CREB/ATF1. Am J Physiol Gastrointest Liver Physiol. 2005;289(5):G949-959. doi:10.1152/ajpgi.00142.2005

71. Kim YD, Kwon EJ, Park DW, Song SY, Yoon SK, Baek SH. Interleukin-1beta induces MUC2 and MUC5AC synthesis through cyclooxygenase-2 in NCI-H292 cells. Mol Pharmacol. 2002;62(5):1112-1118. doi:10.1124/mol.62.5.1112

72. Iwashita J, Sato Y, Sugaya H, Takahashi N, Sasaki H, Abe T. mRNA of MUC2 is stimulated by IL-4, IL-13 or TNF-alpha through a mitogen-activated protein kinase pathway in human colon cancer cells. Immunol Cell Biol. 2003;81(4):275-282. doi:10.1046/j.1440-1711.2003.t01-1-01163.x

73. Hanski C, Riede E, Gratchev A, et al. MUC2 gene suppression in human colorectal carcinomas and their metastases: in vitro evidence of the modulatory role of DNA methylation. Lab Invest. 1997;77(6):685-695.

74. Yamada N, Hamada T, Goto M, et al. MUC2 expression is regulated by histone $\mathrm{H} 3$ modification and DNA methylation in pancreatic cancer. Int $J$ Cancer. 2006;119(8):1850-1857. doi:10.1002/ijc. 22047

75. Akiba Y, Guth PH, Engel E, Nastaskin I, Kaunitz JD. Dynamic regulation of mucus gel thickness in rat duodenum. Am J Physiol Gastrointest Liver Physiol. 2000;279(2):G437-447. doi:10.1152/ ajpgi.2000.279.2.G437

76. Johansson ME, Hansson GC. Immunological aspects of intestinal mucus and mucins. Nat Rev Immunol. 2016;16(10):639-649. doi:10.1038/nri.2016.88

77. McCool DJ, Marcon MA, Forstner JF, Forstner GG. The T84 human colonic adenocarcinoma cell line produces mucin in culture and releases it in response to various secretagogues. Biochem J. 1990;267(2):491-500. doi:10.1042/bj2670491
78. Garcia MA, Yang N, Quinton PM. Normal mouse intestinal mucus release requires cystic fibrosis transmembrane regulator-dependent bicarbonate secretion. $J$ Clin Invest. 2009;119(9):2613-2622. doi:10.1172/JCI38662

79. Halm DR, Halm ST. Secretagogue response of goblet cells and columnar cells in human colonic crypts. Am J Physiol Cell Physiol. 2000;278(1):C212-233. doi:10.1152/ajpcell.2000.278.1. $\mathrm{C} 212$

80. Carlson TL, Lock JY, Carrier RL. Engineering the mucus barrier. Annu Rev Biomed Eng. 2018;20(1):197-220. doi:10.1146/ annurev-bioeng-062117-121156

81. Patel KK, Miyoshi H, Beatty WL, et al. Autophagy proteins control goblet cell function by potentiating reactive oxygen species production. EMBO J. 2013;32(24):3130-3144. doi:10.1038/ emboj.2013.233

82. Grenier JM, Wang L, Manji GA, et al. Functional screening of five PYPAF family members identifies PYPAF5 as a novel regulator of NF-kappaB and caspase-1. FEBS Lett. 2002;530(13):73-78. doi:10.1016/S0014-5793(02)03416-6

83. Wlodarska M, Thaiss CA, Nowarski R, et al. NLRP6 inflammasome orchestrates the colonic host-microbial interface by regulating goblet cell mucus secretion. Cell. 2014;156(5):1045-1059. doi:10.1016/j.cell.2014.01.026

84. Zheng D, Kern L, Elinav E. The NLRP6 inflammasome. Immunology. 2021;162(3):281-289. doi:10.1111/imm.13293

85. Varol C, Vallon-Eberhard A, Elinav E, et al. Intestinal lamina propria dendritic cell subsets have different origin and functions. Immunity. 2009;31(3):502-512. doi:10.1016/j.immuni.2009. 06.025

86. McDole JR, Wheeler LW, McDonald KG, et al. Goblet cells deliver luminal antigen to CD103+ dendritic cells in the small intestine. Nature. 2012;483(7389):345-349. doi:10.1038/ nature 10863

87. Knoop KA, Gustafsson JK, McDonald KG, Kulkarni DH, Kassel R, Newberry RD. Antibiotics promote the sampling of luminal antigens and bacteria via colonic goblet cell associated antigen passages. Gut Microbes. 2017;8(4):400-411. doi:10.1080/ 19490976.2017.1299846

88. Coombes JL, Siddiqui KR, Arancibia-Carcamo CV, et al. A functionally specialized population of mucosal CD103+ DCs induces Foxp3+ regulatory $\mathrm{T}$ cells via a TGF-beta and retinoic acid-dependent mechanism. J Exp Med. 2007;204(8):1757-1764. doi:10.1084/jem.20070590

89. Mora JR, Iwata M, Eksteen B, et al. Generation of gut-homing IgA-secreting B cells by intestinal dendritic cells. Science. 2006;314(5802):1157-1160. doi:10.1126/science.1132742

90. Niess JH, Adler G. Enteric flora expands gut lamina propria CX3CR1+ dendritic cells supporting inflammatory immune responses under normal and inflammatory conditions. J Immunol. 2010;184(4):2026-2037. doi:10.4049/ jimmunol.0901936

91. Knoop KA, Newberry RD. Goblet cells: multifaceted players in immunity at mucosal surfaces. Mucosal Immunol. 2018;11 (6):1551-1557. doi:10.1038/s41385-018-0039-y

92. Knoop KA, McDonald KG, McCrate S, McDole JR, Newberry RD. Microbial sensing by goblet cells controls immune surveillance of luminal antigens in the colon. Mucosal Immunol. 2015;8(1):198-210. doi:10.1038/mi.2014.58

93. Shan M, Gentile M, Yeiser JR, et al. Mucus enhances gut homeostasis and oral tolerance by delivering immunoregulatory signals. Science. 2013;342(6157):447-453. doi:10.1126/ science. 1237910

94. McDonald KG, Wheeler LW, McDole JR, et al. CCR6 promotes steady-state mononuclear phagocyte association with the intestinal epithelium, imprinting and immune surveillance. Immunology. 2017;152(4):613-627. doi:10.1111/imm.12801 
95. Konkel JE, Chen W. Balancing acts: the role of TGF-beta in the mucosal immune system. Trends Mol Med. 2011;17(11):668-676. doi:10.1016/j.molmed.2011.07.002

96. McCauley HA, Guasch G. Three cheers for the goblet cell: maintaining homeostasis in mucosal epithelia. Trends Mol Med. 2015;21(8):492-503. doi:10.1016/j.molmed.2015.06.003

97. Schulz-Kuhnt A, Neurath MF, Wirtz S, Atreya I. Innate lymphoid cells as regulators of epithelial integrity: therapeutic implications for inflammatory bowel diseases. Front Med (Lausanne). 2021;8:656745. doi:10.3389/fmed.2021.656745

98. Gurram RK, Zhu J. Orchestration between ILC2s and Th2 cells in shaping type 2 immune responses. Cell Mol Immunol. 2019;16 (3):225-235. doi:10.1038/s41423-019-0210-8

99. Grondin JA, Kwon YH, Far PM, Haq S, Khan WI. Mucins in intestinal mucosal defense and inflammation: learning from clinical and experimental studies. Front Immunol. 2020;11:2054. doi:10.3389/fimmu.2020.02054

100. Grencis RK, Liew FY, Vickerman K. Th2-mediated host protective immunity to intestinal nematode infections. Philos Trans $R$ Soc Lond B Biol Sci. 1997;352(1359):1377-1384. doi:10.1098/rstb.1997.0123

101. Turqueti-Neves A, Otte M, Schwartz C, et al. The extracellular domains of IgG1 and T cell-derived IL-4/IL-13 are critical for the polyclonal memory IgE response in vivo. PLoS Biol. 2015;13 (11):e1002290. doi:10.1371/journal.pbio.1002290

102. Else KJ, Finkelman FD. Intestinal nematode parasites, cytokines and effector mechanisms. Int J Parasitol. 1998;28(8):1145-1158. doi:10.1016/S0020-7519(98)00087-3

103. Takeda K, Tanaka T, Shi W, et al. Essential role of Stat6 in IL-4 signalling. Nature. 1996;380(6575):627-630. doi:10.1038/ $380627 \mathrm{a} 0$

104. Finkelman FD, Shea-Donohue T, Morris SC, et al. Interleukin-4and interleukin-13-mediated host protection against intestinal nematode parasites. Immunol Rev. 2004;201(1):139-155. doi:10.1111/j.0105-2896.2004.00192.x

105. Khan WI, Blennerhasset P, Ma C, Matthaei KI, Collins SM. Stat6 dependent goblet cell hyperplasia during intestinal nematode infection. Parasite Immunol. 2001;23(1):39-42. doi:10.1046/ j.1365-3024.2001.00353.x

106. Lee JJ, Kim D, Pyo KH, et al. STAT6 expression and IL-13 production in association with goblet cell hyperplasia and worm expulsion of Gymnophalloides seoi from C57BL/6 mice. Korean J Parasitol. 2013;51(5):589-594. doi:10.3347/kjp.2013.51.5.589

107. Sharba S, Navabi N, Padra M, et al. Interleukin 4 induces rapid mucin transport, increases mucus thickness and quality and decreases colitis and Citrobacter rodentium in contact with epithelial cells. Virulence. 2019;10(1):97-117. doi:10.1080/ 21505594.2019.1573050

108. Blanchard C, Durual S, Estienne M, et al. IL-4 and IL-13 up-regulate intestinal trefoil factor expression: requirement for STAT6 and de novo protein synthesis. J Immunol. 2004;172 (6):3775-3783. doi:10.4049/jimmunol.172.6.3775

109. Dosh RH, Jordan-Mahy N, Sammon C, Le Maitre CL. Long-term in vitro $3 \mathrm{D}$ hydrogel co-culture model of inflammatory bowel disease. Sci Rep. 2019;9(1):1812. doi:10.1038/s41598-01938524-8
110. Kim YD, Jeon JY, Woo HJ, et al. Interleukin-1beta induces MUC2 gene expression and mucin secretion via activation of PKC-MEK/ERK, and PI3K in human airway epithelial cells. $J$ Korean Med Sci. 2002;17(6):765-771. doi:10.3346/ jkms.2002.17.6.765

111. Turner JE, Stockinger B, Helmby H, Wynn TA. IL-22 mediates goblet cell hyperplasia and worm expulsion in intestinal helminth infection. PLoS Pathog. 2013;9(10):e1003698. doi:10.1371/journal.ppat. 1003698

112. Reyes JL, Fernando MR, Lopes F, et al. IL-22 restrains tapeworm-mediated protection against experimental colitis via regulation of IL-25 expression. PLoS Pathog. 2016;12(4): e1005481. doi:10.1371/journal.ppat.1005481

113. Sugimoto K, Ogawa A, Mizoguchi E, et al. IL-22 ameliorates intestinal inflammation in a mouse model of ulcerative colitis. $J$ Clin Invest. 2008;118(2):534-544. doi:10.1172/JCI33194

114. Keir M, Yi Y, Lu T, Ghilardi N. The role of IL-22 in intestinal health and disease. J Exp Med. 2020;217(3):e20192195. doi:10.1084/jem.20192195

115. Correa I, Veny M, Esteller M, et al. Defective IL-10 production in severe phenotypes of Crohn's disease. J Leukoc Biol. 2009;85 (5):896-903. doi:10.1189/jlb.1108698

116. MacDonald TT. Gastrointestinal inflammation. Inflammatory bowel disease in knockout mice. Curr Biol. 1994;4(3):261-263. doi:10.1016/S0960-9822(00)00060-9

117. Tagore A, Gonsalkorale WM, Pravica V, et al. Interleukin-10 (IL-10) genotypes in inflammatory bowel disease. Tissue Antigens. 1999;54(4):386-390. doi:10.1034/j.1399-0039.1999. 540408.x

118. Keubler LM, Buettner M, Hager C, Bleich A. A multihit model: colitis lessons from the interleukin-10-deficient mouse. Inflamm Bowel Dis. 2015;21(8):1967-1975. doi:10.1097/MIB.00000 00000000468

119. Xue Y, Zhang H, Sun X, Zhu MJ. Metformin improves ileal epithelial barrier function in interleukin-10 deficient mice. PLoS One. 2016;11(12):e0168670. doi:10.1371/journal.pone.0168670

120. Johansson ME, Gustafsson JK, Holmen-Larsson J, et al. Bacteria penetrate the normally impenetrable inner colon mucus layer in both murine colitis models and patients with ulcerative colitis. Gut. 2014;63(2):281-291. doi:10.1136/gutjnl-2012-303207

121. Hasnain SZ, Tauro S, Das I, et al. IL-10 promotes production of intestinal mucus by suppressing protein misfolding and endoplasmic reticulum stress in goblet cells. Gastroenterology. 2013;144 (2):357-368e359. doi:10.1053/j.gastro.2012.10.043

122. Waddell A, Vallance JE, Moore PD, et al. IL-33 signaling protects from murine oxazolone colitis by supporting intestinal epithelial function. Inflamm Bowel Dis. 2015;21(12):2737-2746. doi:10.1097/MIB.0000000000000532

123. Schmitz J, Owyang A, Oldham E, et al. IL-33, an interleukin-1-like cytokine that signals via the IL-1 receptor-related protein ST2 and induces $\mathrm{T}$ helper type 2-associated cytokines. Immunity. 2005;23(5):479-490. doi:10.1016/j.immuni.2005.09.015

124. Imaeda $\mathrm{H}$, Andoh $\mathrm{A}$, Aomatsu $\mathrm{T}$, et al. Interleukin-33 suppresses Notch ligand expression and prevents goblet cell depletion in dextran sulfate sodium-induced colitis. Int J Mol Med. 2011;28 (4):573-578. doi:10.3892/ijmm.2011.718 


\section{Publish your work in this journal}

The Journal of Inflammation Research is an international, peerreviewed open-access journal that welcomes laboratory and clinical findings on the molecular basis, cell biology and pharmacology of inflammation including original research, reviews, symposium reports, hypothesis formation and commentaries on: acute/chronic inflammation; mediators of inflammation; cellular processes; molecular mechanisms; pharmacology and novel anti-inflammatory drugs; clinical conditions involving inflammation. The manuscript management system is completely online and includes a very quick and fair peerreview system. Visit http://www.dovepress.com/testimonials.php to read real quotes from published authors. 